\title{
Conceptual Frameworks for Strategy Implementation: A Literature Review
}

\author{
Maher Hourani \\ Faculty of Economics and Business Administration \\ Sofia University \\ E-mail: maher.hourani6@gmail.com
}

Received: April 12, $2017 \quad$ Accepted: June 4, $2017 \quad$ Published: July 1, 2017

doi:10.5296/jmr.v9i3.11222 URL: https://doi.org/10.5296/jmr.v9i3.11222

\begin{abstract}
Strategy implementation is one of the four pillars of strategic management. It has gained considerable attention of a large number of researchers as well as practitioners. This is growing attention due to the publication of scary percentage of limited success of strategy implementation in many worldwide business organizations. This paper presents a literature review of a number of important conceptual frameworks for strategy implementation. This paper is a humble attempt towards proposing a novel conceptual framework which can help in drawing big picture of key factors affecting strategy implementation success.
\end{abstract}

Keywords: Conceptual frameworks, Strategy implementation, Internal factors, External factors, Balanced Scorecard. 


\section{Introduction}

Despite the clear importance of strategic management area and the obvious problems associated with its execution, it has however, been substantially neglected by academics (Atkinson, 2006). For many managers, strategy formulation is difficult while executing or implementing it throughout the organization is even more difficult without effective implementation, no business strategy can succeed. Unfortunately, most managers know far more about developing strategy than they do about executing it (Hrebiniak, 2006). The effectiveness of whole process of planning diminishes if the formulated strategies are not implemented (Siddique and Shadbolt, 2016). Remarkably, organizations fail to implement about $70 \%$ of their new strategies (Franklen et al, 2009). According to Johnson (2004), 66\% of corporate strategy is never executed. According to Kaplan and Norton (1996), 95\% of a company employees are unaware of or do not understand their company strategy.

\subsection{Defining Strategy Implementation}

Strategy implementation involves a broad range of efforts which focus on the transformation of strategic intentions into action (Miller and Dess, 1996). As for Noble (1999), strategy implementation is defined as: The communication, interpretation, adoption, and enactment of strategic plans. For Wheelen and Hunger (2012), implementing a strategy involves taking ideas, decisions, plans, policies, objectives and other aspects of the chosen strategy and implementing them into action.

Strategy implementation is an iterative process of implementing strategies, policies, programs and action plans that allows a firm to utilize its resources to take advantage of opportunities in the competitive environment (Harrington,2006). Implementation is the actions initiated within the organization and its relationships with external constituencies to realize the strategy (Homburg et al, 2004).

Implementation in a hands-on operation and action-oriented human behavioral activity that calls for executive leadership and key managerial skills (Schaap, 2006). Strategy implementation is about designing appropriate organizational structure and control systems to put the organization chosen strategy into action (Hill et al, 2007).

For Wheelen and Hunger (2012), strategy implementation is the sum total of the activities and choices required for execution of a strategic plan. Li et al (2008) concluded from 60 articles that they have reviewed, three distinct conceptions of the term "strategy implementation"; the first approach concentrate on a "process perspective" and takes strategy implementation as a sequence of carefully planned consecutive steps. The second approach treats strategy implementation as a series of more or less concerted (but often parallel) actions and examines these actions from a "behavior perspective". Some authors combine the process perspective and behavior perspective and form a third approach, which Yang et al called it as "hybrid perspective".

This study stands for the adoption of Wheelen and Hunger (2012) definition of strategy implementation due their comprehensive perspective as one of four pillars that forms the strategic management basic integrated elements (Environmental scanning, strategy 
formulation, strategy implementation and evaluation).

\section{A Review of Conceptual Models and Frameworks for Strategy Implementation}

Models are theoretical systematic grouping of interdependent concepts and principles that give a framework to, or tie together, a significant area of knowledge as scattered data are not information unless observer has knowledge of the theory that will explain relationships (Olum, 2004). Thus theories and theoretical models, provides criteria for what is relevant, they enable us communicate efficiently and they challenge us to keep learning about our world or the field we operate in as the environment is ever changing (Chiuri, 2015).

There are some commonly used models and framework available for researchers and managers in the areas of strategy analysis and formulation in strategic management such as SWOT analysis, Porter's generic strategies, portfolio models (Okumus, 2003, Wheelen and Hunger, 2012). By contrast, there is no agreed-upon, generally accepted and dominant framework in "strategy implementation" (Siddique and Shadbolt, 2016).

Kurt Verweire (2014) considers that some management authors see strategy implementation as a performance measurement and management exercise, where strategies are translate into key performance indicators (KPI) that you cascade further down the organization. Others see strategy implementation as creating an organizational culture that empowers people to act in line with the strategy. Still others see implementation as strategic project portfolio management. Strategy implementation is all of that, and even more, strategy execution is a broad domain that touches many different management areas, from direction and goal-setting to HR, operations culture and the quality of leadership team that is in charge. So managers should pay significant attention to developing an engaging organizational climate and collaborative structure and culture.

Much of strategy implementation research has focused on executing strategy as an operational process with related outcomes, instead of linking strategy implementation with strategic competitive performance outcomes (Hutzschenreater and Kleindienst, 2006); (Dederiches, 2010).

Reviewing strategy implementation literature shows that most approaches about strategy implementation may be categorized in two groups; the first considered the term of strategy implementation as a sum of factors that interplays, interacts, and integrates within strategy implementation. This second group of approaches considered the term strategy implementation as "process", therefore this group may be called as "process- oriented" approaches (Amjad, 2013).

Whether approaches are "factor-oriented" or "process-oriented", in their attempts to develop conceptual frameworks of strategy implementation, this study will categorize the most important of these attempts by focus area as shown in Table (1). 


\section{Macrothink}

Journal of Management Research

ISSN 1941-899X

2017, Vol. 9, No. 3

Table 1. [Strategy implementation conceptual frameworks attempts by category of approaches focus area]

\begin{tabular}{|c|c|c|}
\hline $\begin{array}{c}\text { Category of } \\
\text { Strategy } \\
\text { Implementation } \\
\text { Approach }\end{array}$ & $\begin{array}{l}\text { Conceptual Model / Framework Components } \\
\text { (Factors / Actions) }\end{array}$ & Authors / Researchers \\
\hline $\begin{array}{l}\text { Factor-oriented } \\
\text { approaches }\end{array}$ & $\begin{array}{l}\text { - Structure } \\
\text { - Interpersonal-behavior } \\
\text { - Strategic consensus, understanding, and } \\
\text { - } \text { strategy formulation quality } \\
\text { - Commitment } \\
\text { - } \text { Ceadership, power structure } \\
\text { - Culture, shared values } \\
\text { - Resource allocation } \\
\text { - HR, people development, empowerment and } \\
\text { - } \text { reward } \\
\text { - } \text { Sanagement mechanism and control } \\
\text { - Cxternal factors PESTEL/ task environment } \\
\text { Compertainty, competitors) }\end{array}$ & $\begin{array}{l}\text { Waterman and Phillips (1980), } \\
\text { Hrebiniak (2005),(2006),(2013), } \\
\text { Hill et al (2007), Schaap (2006) } \\
\text { Pryors et al (2007), Brenes et al } \\
\text { (2008), Olson et al (2005), Olums } \\
\text { (2004), Hill and Jones (2008), } \\
\text { Aakar (1998), Brinkschroder N., } \\
\text { (2014), } \\
\text { Verweir (2014), } \\
\text { Hrebiniak (2008), (2013), } \\
\text { Okums (2001), (2003), Siddique } \\
\text { and shdbolt (2016). }\end{array}$ \\
\hline $\begin{array}{l}\text { Process-oriented } \\
\text { Approaches }\end{array}$ & $\begin{array}{l}\text { - Strategy-as-practice (Strategizing), } \\
\text { - Implementation process barriers / drivers } \\
\text { - Strategy implementation as iterative process } \\
\text { - Strategy-process }\end{array}$ & $\begin{array}{l}\text { Pettigrew (1997), Whittington } \\
\text { (2006), Jazabkowski et al (2007), } \\
\text { Li et al (2008), Anderson (2004), } \\
\text { Harrington (2006), Jazabkowski } \\
\text { and Whittington (2008), Dameron } \\
\text { and Torset (2014), Cardoso and } \\
\text { Lavardo (2011), Da Costa et al } \\
\text { (2015), Grand (2001), } \\
\text { Hutzschenreuter and Kleindienst } \\
\text { (2006) }\end{array}$ \\
\hline
\end{tabular}

2.1 Strategy implementation conceptual "factor-oriented", and "process-oriented" approaches:

2.1.1 "Factor-oriented" approaches of strategy implementation:

This study highlights eight of the most important contributions conceptual models in strategy implementation:

(1) Waterman and Phillips's model (1980)/ (Mckinsey 7's) 


\section{Macrothink}

Waterman and Philips (1980) proposed a strategy implementation framework in their article "Structure is not organization" in Business Horizons 1980. One of the three authors, "Peters", explained how the 7(S's) key factors became to be best known as Mckinsey's 7S, saying that Ron Daniel, Mckinsey managing directors was bedeviled by frequency with which clever strategies failed to be implemented effectively (Peters and Bay, 2011). The 7s model is the fruit of three research stations; "structure is not organization" 1980 Business Horizons article. Then Athos and Pascale research "The art of Japanese Management (1981), and Waterman and Peters included it in "In search of Excellence" (1982) (Peters and Bay, 2011).

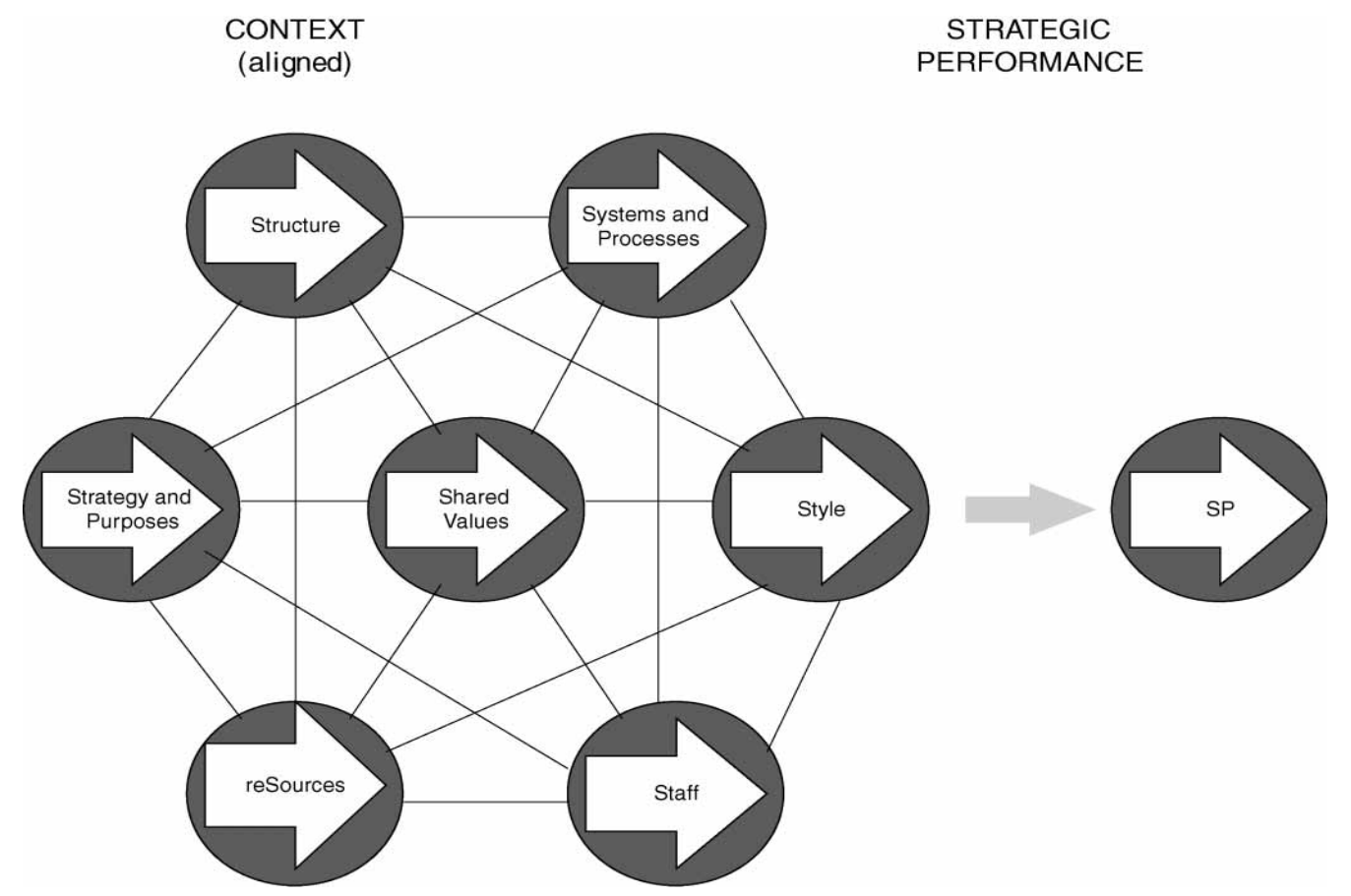

Figure 1. Waterman and Phillips, Conceptual framework (1980)/ (Mckinsey 7's)

(2) Aaker's conceptual framework (1998)

In his book "Developing Business Strategy", Aaker (1998) proposed a conceptual framework which aimed to help business in identifying factors that are to be considered in actual and potential strategy implementation problems. He suggested that these components must fit with each other as well as with the strategy. 


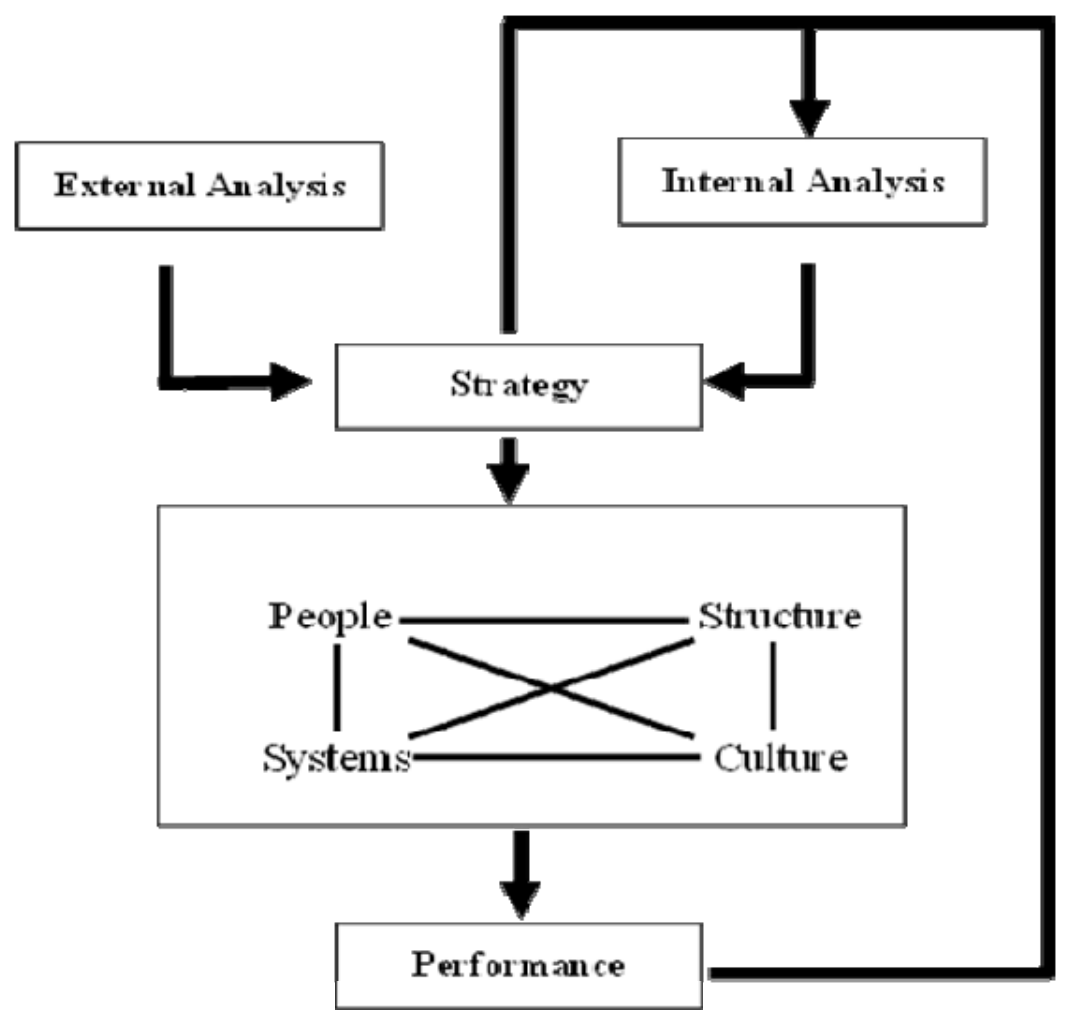

Figure 2. Aaker's Conceptual framework for analyzing organization and strategy implementation requirements (1998)

(3) Okumus's Conceptual framework of strategy implementation (2001), (2003).

Okumus (2001) identified ten key variables which were critical for strategy implementation. These include: (strategy formulation, environmental uncertainty, organizational structure, culture, operational planning, communications, resource allocation, people, control and outcome). In (2003), Okumus developed his (2001) framework after identifying eleven key implementation factors and succeeded in regrouping them into four categories: (strategic content, strategic context, process and outcome). Based on this categorization Okumus (2003) proposed a conceptual framework renewing his (2001) model; to become with emphasized the interaction effect of the variables involved as shown in figure (7). Okumus (2003) further clarified that different implementation factors in these four categories should not be evaluated in isolation because a factor in one group can influence the other factors in the same and in other group. 


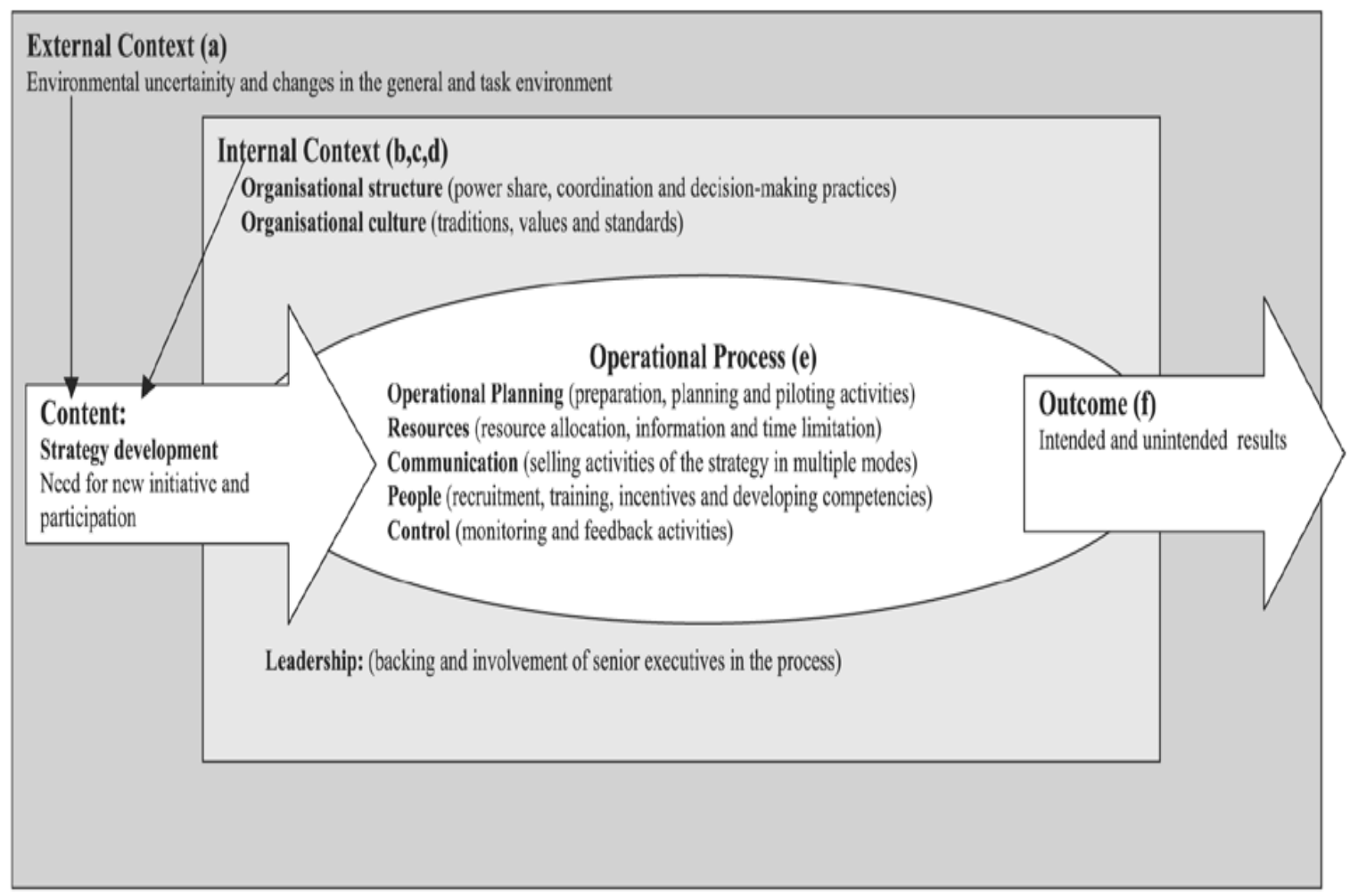

Key

a Changes in the external environment influence the strategic context and force organizations to deploy new initiatives.

b Problems and inconsistencies in the internal context require new initiatives.

c The strategy is implemented in the internal context, and the characteristics of organizational structure, culture and leadership influence the process factors.

d Having an organizational context that is receptive to change is essential for the successful implementation of strategy.

e The process factors are primarily used on a continuous basis to implement the strategy and manipulate the internal context.

f The characteristics of the context and process factors and how they are used directly influence the outcomes.

Figure 3. [Okums strategy implementation conceptual framework]

(4) Pryor et al (2007) Conceptual framework [5P's Model]

Pryor et al. (2007) proposed a conceptual framework based on the alignment and integration of widely accepted activities and functions of effective and successful strategy implementation. These activities and functions include: (structure, systems, leadership behavior, human resource policies, culture, values and management processes).

Pryor et al. (2007) advocated the inevitable intertwined elements of culture, organization, people, and systems for strategy implementation and put forward a broad, process oriented interpretation of these elements in the form of "the 5P's model of strategy implementation". 


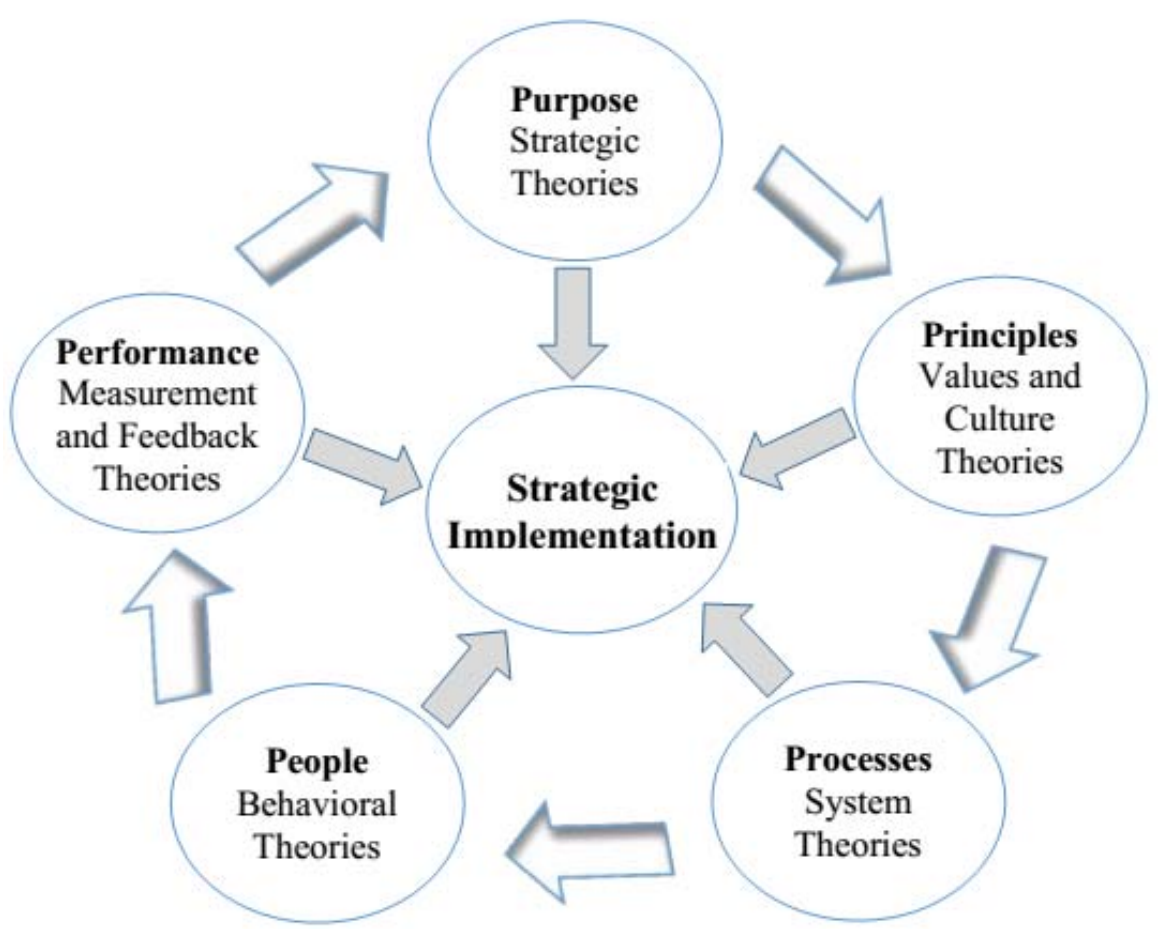

Figure 4. [5Ps model of strategy implementation Pryor et al (2007)]

(5) Hill and Jones Conceptual framework (2008)

For both Hill and Jones (2008), the organizational design is the heart of implementing strategies effectively. Organizations motivate and coordinate its employees and members through the use of organizational structure, control systems and culture to work towards achieving the desired results by developing the competitive advantage. They also believed that organizational structure, control systems and culture directly affect the behavior, values and attitudes of people and also help them in implementing the organization business model and strategies.

Hitt, Ireland, and Hoskinson (2013), also developed their conceptual framework, they share with Brenes et al (2008), the important role of corporate governance in strategy implementation success. According to Hitt et al. (2013) effective corporate governance, organizational structure and strategic entrepreneurships are necessary for successful implementation of strategies. Corporate governance is a relationship among stakeholders and helps determining the direction of firms and also control its performance.

Hitt et al (2013) believes that organization structure specifies the accomplishment of given tasks whereas organizational control provides alignment to these tasks according to the strategic intent and also suggests improvements in performance when it falls below expectations. 


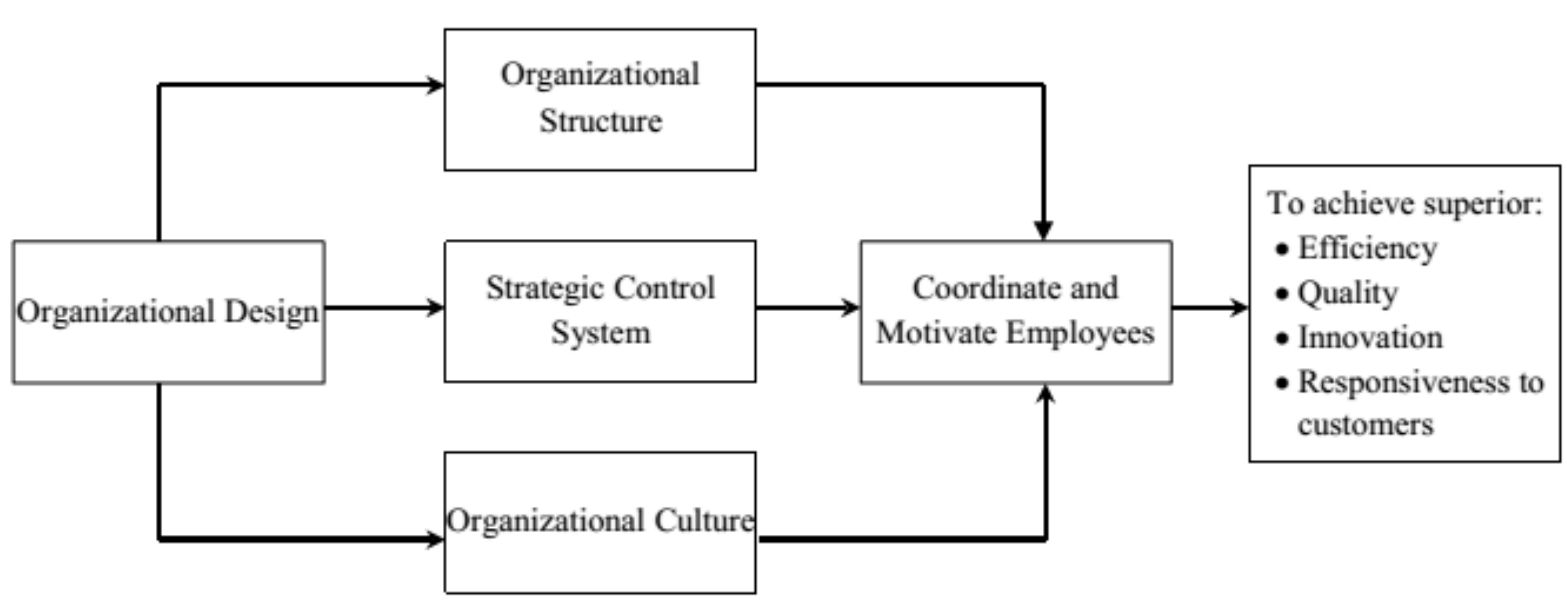

Figure 5. The Hill and Jones conceptual framework (2008)

(6) Brenes et al. Conceptual framework (2008): (Five key dimensions in successful implementation of strategy)

In 2008, Brenes and his colleagues found that most successful companies between 300 local business firm in Latin America, reported the top three dimensions that included: (corporate governance leading the change, CEO's leadership and suitable motivated management and employees, and the strategy formulation process).

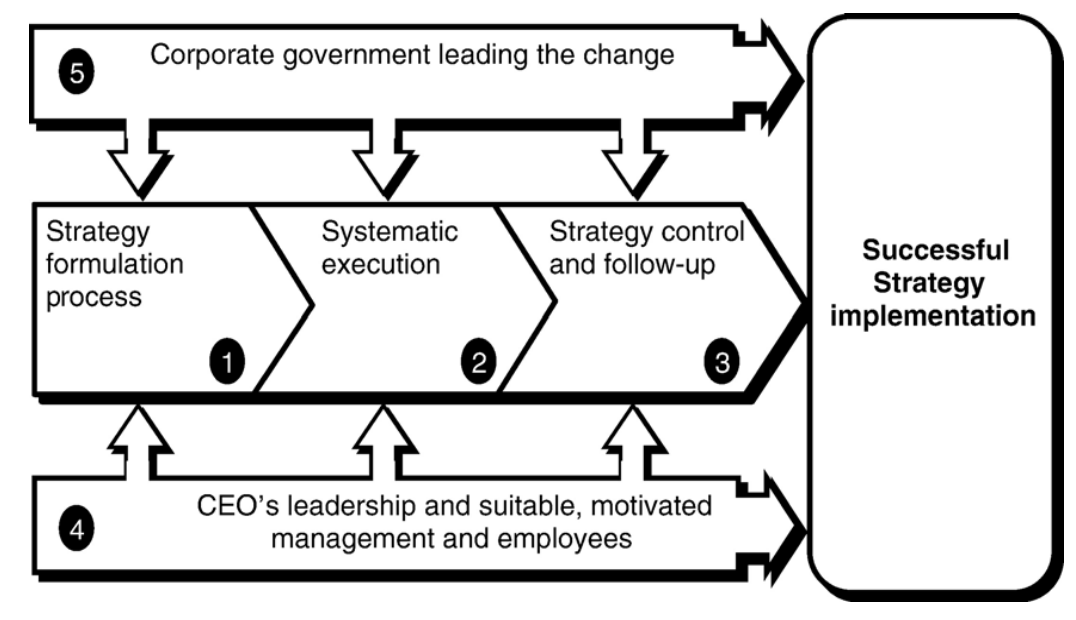

Figure 6. Brenes et al (2008) Conceptual framework of Five key dimensions in successful strategy implementation.

(7) Hrebiniak's Conceptual framework "implementing strategy and contextual factors" (2005), (2008), and (2013).

Hrebiniak in his book; "Making Strategy Work" (2013), clarified that implementing strategy takes place within an organizational or environmental context. The four major factors, for Hrebiniak (2013) includes: (the change management context, the culture of the organization, the organizational power structure, and the leadership context). Hrebiniak concluded that the inability to manage change (considering some of the organizational characteristics, as the 
size of the change and the time to manage it), can be one of the biggest obstacle to implement strategy successfully .

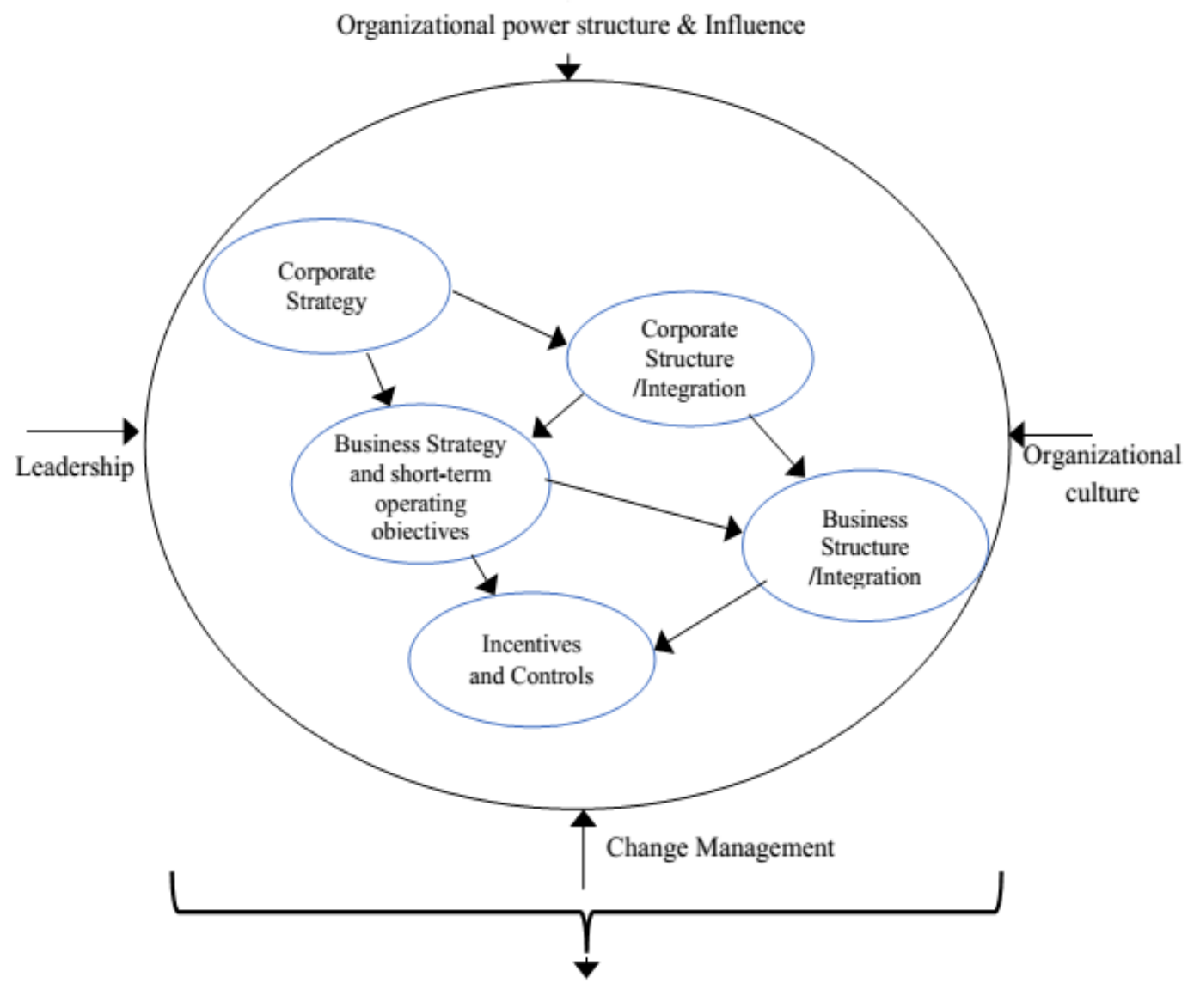

Execution Results

Figure 7. Hrebiniak Conceptual framework [Implementation strategy and contextual factors].

(8) Verweire's conceptual framework of strategy implementation (2014):

Kurt Verweire (2014) constructed a model to capture the essential elements of what constitutes effective strategy implementation. Three main levels for achieving a competitive advantage and a winning performance. The first lever of competitive advantage relates to the "Strategy itself". It does not make sense to implement a low-quality strategy.

The two other levers concentrate on how to translate a winning strategy into great results: "Alignment" that defines which activities your company should set up to make the strategy concrete. The third lever of competitive advantage "Commitment" as a major determinant of organizational effectiveness; deals with the organizational context in which a firm's activities occur (Verweire, 2014).

Winning companies have a highly committed workforce that is able to provide relevant input in the organization strategic discussions, as well as to translate the strategy into the 


\section{Macrothink}

organization day-to-day activities. The whole organization is "strategy-focused", not just the executive team. The result is an organization that is "performance-driven", yet thrives on a collaborative and participative culture. Effective strategy implementation requires managers to work on all three levers - strategy, alignment and commitment - to create a sustainable competitive advantage.

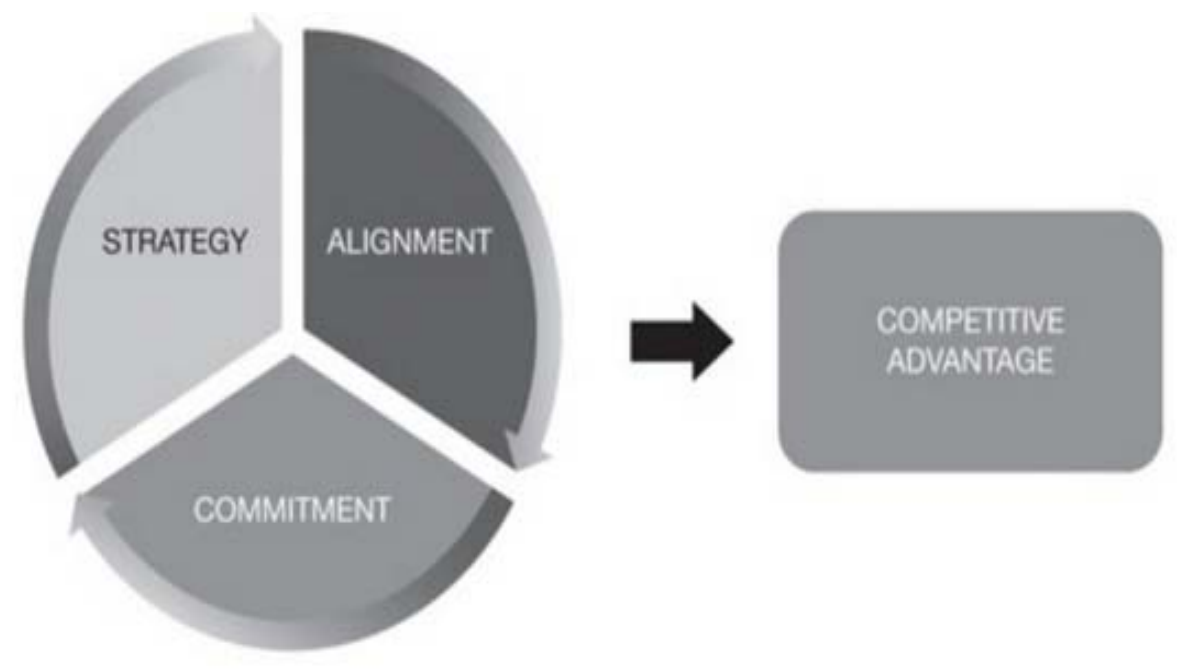

Figure 8. Verweire Conceptual framework [Three Levers of Competitive Advantage] (2014)

\subsection{2 "Process oriented" approach of strategy implementation}

The rapid growth in the field of strategy-as-practice research may be attributed to a general unease with the way that strategy research has developed over the last three decades. Since 1980 's the landmark contributions by Michael Porter strategy research has largely been based on the micro-economic tradition. As a consequence, research has typically remained on the macro-level of firms and markets while reducing strategy to a few causally related variables in which there is little evidence of human actions. In order to understand human agency in the construction and enactment of strategy, it is necessary to re-focus research on the action and interactions of the strategy practitioner in doing strategy. Strategy-as-practice may thus be seen as a part of the broader concern to humanize management and organization research (Pettigrew, 1997). For Whittington (2006), the Strategy-as-practice approach emphasize explicit links between micro and macro perspectives on strategy as a social practice. 


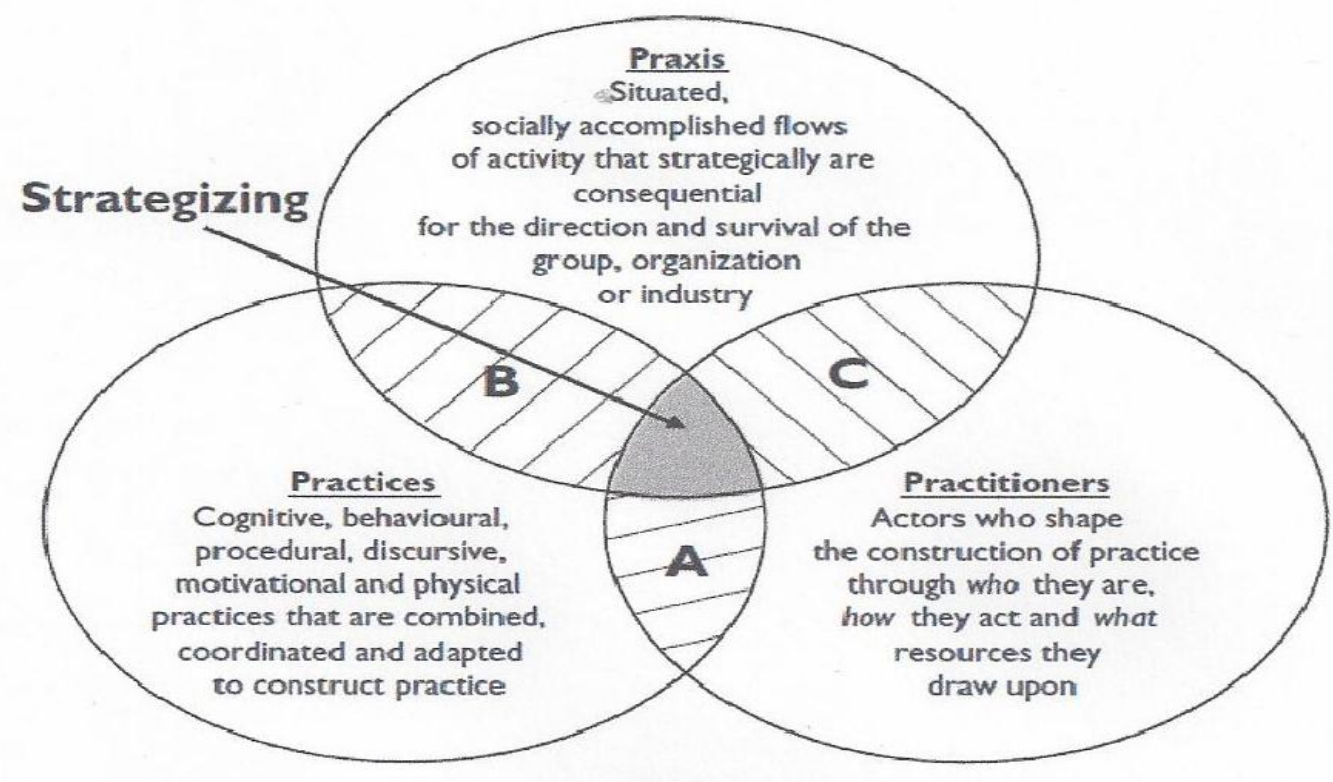

Figure 9. Whittington Strategy-as-practice conceptual model (2006)

For a comprehensive understanding of "Strategizing" Strategy-as-practice model, Whittington (2006) proposed three elements may be isolated, praxis, practices and practitioners. "Praxis" comprises the interconnection between the actions of different, dispersed individuals and group and those socially, politically, and economically embedded institutions within which individuals act and to which they contribute. This definition is important, as it indicates that "praxis" is both an embedded concept that may be operationalized at different levels from the institutional to the micro, and also dynamic, shifting fluidly through the interactions between levels (Jarzabkowski et al, 2007).

"Practices" is intrinsically connected to "doing" because they provide the behavioral, cognitive, procedural, discursive and physical resources through which multiple actors are able to interact in order to socially accomplish collective activity. As these resources are utilized in routinized way that form patterns, they may be studied to understand "how" strategic activity is constructed (Jarzabkowski et al, 2007).

Finally, "Practitioners" are obvious units of analysis for study, being active participants in the construction of activity that is consequential for the organization and its survival. However, identifying relevant practitioners and analyzing how their actions impact upon strategic activity is a complex issue that opens many new arenas of research.

For $\mathbf{A}, \mathbf{B}$ and $\mathbf{C}$ areas in figure (9), A is the interconnection between "practitioners" and "practice". B is the interconnection between "practices" and practice. C is the interconnection between "practitioners" and practice. The remaining area in the middle is core of "Strategizing" process.

The (SAP) Strategy-as-practice/strategizing model still confronting a big deal of ongoing challenges. Although there has been impressive empirical progress given the nascent state of 
Strategy-as-practice as a field. However, contribution of this field may be further exploring the issues raised by the keys in this conceptual framework. Raised by the key in this conceptual framework of "praxis", "practice" and "practitioners" and their relationships. The key priority is for more empirical research, which has been explicitly framed and designed to address the (SAP) research agenda.

The actual strategizing practice of attracting and developing firm resources thus will substantially shape the resulting firm strategy and performance. However, despite the significance of the approach, the perspective has been challenged as being conceptually vague and tautological, focused on intangible and hard to observe concepts. While the detailed analysis of the strategizing practice in strategy research often suffers from a local and descriptive bias, its re-interpretation in a dynamic capability perspective guarantees an explicit interest in the link between differences with respect to their strategizing practices, differences in firm strategy, and differences in the resulting firm performance (Grand, 2001).

An overview to the "process-oriented" approach to strategy implementation show that this approach has been influenced by scholars conceptualization of implementation within the strategy process (Sminia, 2009), (Hutszchenreuter and Kleindienst, 2006). The key issues of this approach are the intentionality and rational structuring versus the emergence of strategy and how distinct strategy implementation is considered in the strategy process (Dameron and Torset, 2014).

Some process-oriented literature focused on strategic change, however, there is a need to conduct implementation research for strategic continuity as well. The issue of organizational buy-in management leadership, provision of the required culture, and strategy communication to the organization became the focus of implementation process-oriented research ( $\mathrm{Li}$ et al., 2008).

The strategy-as-practice view is an attempt to look at practitioners, practices and praxis involved in strategic activities within organization. Although there are some major difference in the details and emphasis between proponent of the "strategy-as-process" and "strategy-as-practice" view (Whittington, 2007), there is an agreement that both share a ( processual) view of strategy implementation (Langley, 2007).

\subsection{Balanced Scorecard approach for assessing strategy implementation success}

This paper, referring to what Robert S. Kaplan (2010) argued, "Norton and I believed that : "if you cannot measure it, you cannot improve it". In fact, Kaplan (2010), continue in his working paper for the Harvard Business school: "after publication of the 1992, 1996 HBR article, several companies quickly adopted the balanced scorecard giving us deeper and broader insights into its power and potential. During the next 15 years, as it was adopted by thousands of private, public and nonprofit enterprises around the world, we extended and broadened the concept into management tool for describing, communicating and implementing strategy" (Kaplan, 2010).

This paper stands for the idea that any conceptual framework to be successfully developed must illustrate, in its design, a cause-effect relationship between the context's factors of 
strategy implementation process(during implementing). Thus, using Balanced Scorecard four perspectives; Financial, Customers, Internal process, and learning and growth, will allow measuring objectively the degree of achieved outcomes success of strategy implementation.

\section{Obstacles of Strategy Implementation Success}

Developing a sound strategy is only half the battle; the more difficult task is confronting the obstacles that prevent leaders from executing their strategies. There are a multitude of reasons proffered to explain why planning and execution sometimes fail to deliver expected performance (AMA/ American Management Association, 2006-2016).

Each firm is unique in terms of its portfolio of products and markets, its resources and capabilities, its corporate culture, its administrative heritage, its structure, systems, leadership style, and the external environment together, can describe organizational identity and overall configuration in achieving success to formulating and implementing any organization corporate strategy. Regarding that internal fit is not enough; the critical requirement and the key of this complexity, is fit with external environment as well, the strategic fit is the key (Grant, 2010).

Kurt Verweir (2014) argued the issue of strategy implementation obstacles, said that; "in many discussions with managers who struggle with strategy implementation, he have discovered that there are five root causes for unsuccessful strategy implementation":

- There is too much focus on financials in strategy discussion.

- $\quad$ Functional strategies are not substitute for a business strategy.

- Strategy implementation is too fragmented.

- Managers communicate about strategy but forget to translate strategy into action.

- Strategy implementation requires leadership capabilities.

Wheelen and Hunger (2012) considered the following problems in implementing strategy:

1. Implementation took more time than originally planned.

2. Unanticipated major problems arose.

3. Activities were ineffectively coordinated.

4. Competing activities and crisis took attention away from implementation.

5. The involved employees had insufficient capabilities to perform their jobs.

6. Lower-level employees were inadequately trained.

7. Departmental managers provided inadequate leadership and direction.

8. Key implementation tasks and activities were poorly defined.

9. The information system inadequately monitored activities. 
As for the AMA (2006-2016), the listed "Top ten factors hindering strategic execution"; with (expectations go for 10 years, till 2016), took the ranking by relative importance in a scale of 5 -points, where $1=$ very little and 5= very much.

Table 2. [Top Ten Factors Hindering Strategic Execution] seen by AMA 2006 and expectation in ten years, ( 5 points scale relative importance):

\begin{tabular}{|l|c|c|}
\hline \multicolumn{1}{|c|}{ Factors } & (2006) & $\begin{array}{c}\text { In Ten years } \\
(\mathbf{2 0 1 6 )}\end{array}$ \\
\hline Lack of adequate resources & 3.18 & 3.00 \\
\hline Government regulations & 3.09 & 3.17 \\
\hline Lack of follow-through & 3.08 & 2.85 \\
\hline Competitive pressures & 3.06 & 3.24 \\
\hline Inadequate communication and feedback & 3.06 & 2.88 \\
\hline Lack of performance management links to outcomes & 3.03 & 2.75 \\
\hline Culture not ready for change & 3.02 & 2.74 \\
\hline Economic conditions are not favorable & 3.01 & 3.33 \\
\hline Confusion over goals or expectations & 2.99 & 2.78 \\
\hline Conflicting accountabilities & 2.98 & 2.86 \\
\hline
\end{tabular}

In this study, we believe that obstacles and problems that could hinder strategy implementation or causing its failure; should be included as a part of a comprehensive conceptual model as it is proposed in this study. In fact surrounding both internal and external factors affecting strategy implementation outcomes success and examining them empirically will permit further conclusions in the Jordanian private universities as the case of this study.

\section{Conclusions}

Strategy implementation represents one of the four pillars of strategic management. This paper reviews theoretical literature on strategy implementation, and reveals some conclusions and important pints:

1. As Wheelen and Hunger (2012) summarized, strategy implementation is "Where the rubber hits the road". Environmental scanning and strategy formulation are crucial to strategic management but are only the beginning of the process. The failure to carry a strategic plan into day-to-day operations of the workplace is a major reason why strategic planning often fails to achieve its objectives.

2. Whether a researcher adopt the "Factor-oriented" or the "Process-oriented" or any other approaches in formulating a conceptual model for strategy implementation, it is vital to consider that they all will meet others at the end, due that all attempts seek "success" for the strategy implementation outcomes but by different ways.

3. It would be an exaggerated simplifying to investigate probable affects on strategy implementation success by focusing only on internal context factors. The big picture shows that business organizations as open systems, exchange affects with their external environment as well. 
4. Assessing objectively the validity of any conceptual mode / framework needs to be tested and re-tested empirically, before deciding their validation in the real situations. Empirical analysis of different factors and groups of variables involved in the strategy implementation process when in reality. Strategy implementation is a cyclic process and different variables interact with each other linearly as well as non-linearly.

Therefore, any scientific attempt seeking objectivity in studying or investigating the subject of strategy implementation success factors, is invited to consider having a comprehensive view . Able to surround both internal and external contexts while seeking factors affecting formulated strategy execution process, regarding the use of: Balanced Scorecard approach with its four perspectives; (Financial, Customers, Internal process, and learning and growth), as well as other strategy implementation obstacles. Such a comprehensive view could allow measuring objectively the degree of achieved outcomes success of strategy implementation enhancing wide horizons of improvement .

\section{References}

Aaker, D.A. (1998). Developing Business Strategy. 5th Edition, by John Wiley and Sons Inc., New York.

AMA, American Management Association. (2006-2016). The Keys to Strategy Execution. a global study of current trends and future possibilities.

Amjad, A. (2013). Towards Competitive Theorization of Strategy Implementation Process-empirical evidence from Applying The RBV Lens on Implementation Process. PhD Thesis, University of Central Lancashire, UK, May 2013.

Anderson, T.J. (2004). Integrating The Strategy Formulation Process: An International Perspective. The European Management Journal, 22(3), 263-272. https://doi.org/10.1016/j.emj.2004.04.008

Atkinson, H. (2006). Strategy Implementation: A Role for Balanced Scorecard. Management Decision, 44(10), 1441-1460. https://doi.org/10.1108/00251740610715740

Brenes, E.R., Mena, M., \& Molina, G.E. (2008). Key Success Factors for Strategy Implementation in Latin America. Journal of Business Research, 61(6), 590-598. https://doi.org/10.1016/j.jbusres.2007.06.033

Brinkschroder N. (2014). Strategy Implementation: Key Factors, Challenges and Solutions. $\mathrm{PhD}$ Thesis Abstract, university of Twente Netherlands. Copyright, http://www.purl.utwente.nl.

Cardoso, F.E., \& Lavarda R.A.B. (2011). Strategy Implementation: Practical Activities Implementing The Deliberate Strategy. V Encontro de Etuelos em Estategia, Porto Alegre/RS- 15 a 17 de Maio de 2011.

Chiuri, B. W. (2015). Challenges of Strategy Implementation in Higher Education Institutions 
in Kenya. PhD Thesis, Jomo Kenyatta University of Agriculture and Technology.

Da Costa R., L., Nelson A., \& Isabel M., (2015). Consultant as Strategic practitioners. Business, Management and Economics Research, 1(8), 107-118.

Dameron, S., \& Torset, C. (2014). The Discursive Construction of Strategist's Subjectivities: Towards a Paradox Lens on Strategy. Journal of Management Studies, 51(2), March. https://doi.org/10.1111/joms.12072

Dederichs, J. (2010). Strategy-As-practice: Implementing An External Growth Strategy Within a Subsidiary" PhD Thesis, University of Surrey UK.

Franklen, A., Edwards, C., \& Lambert, R. (2009). Understanding The Critical Management Elements That Lead to Success. California Management Review, 51(3).

Grand, S. (2001). Building Strategizing Capabilities in Entrepreneurial Firms. Electronic paper accepted at the nelson and Winter Conference in Aalborg, Denmark, June 12th-15th 2001. http://www.simon.grand@unisg.ch.

Grant R., M. (2010). Contemporary Strategy and Analysis. 7th Edition by John Wiley and Sons, Ltd, Publication United Kingdom.

Harrington, R. (2006). The Moderating Effects of Size, Managers Tactics and Involvement on Strategy Implementation in Food Service. Hospitality Management, 2. https://doi.org/10.1016/j.ijhm.2005.02.004

Hill, C.W, \& Jones, G.R. (2009). Theory of Strategic Management. 8th Edition by South-Western Cengage learning, Canada 2009.

Hill, C.W.L., \& Jones, G.R. (2008). Strategic Management: An Integrated Approach. 8th Edition, by Houghton Mifflin, Boston USA.

Hill, C.W.L, Jones G.R, Galvin, P, \& Haidar, A. (2007). Strategic Management: An Integral Approach. 2nd Edition, by John Wiley and Sons, Australia, 2007.

Hitt, M.A., Ireland, R., D., \& Hoskinson, R.E (2013). Strategic Management: Competitiveness and Globalization. 10th Edition, by Mason Cengage Learning, USA.

Homburg, C., Krohmer, H., \& Workman, J.P. (2004). A Strategy Implementation Perspective of Market Orientation. Journal of Business Research, 57, 1331-1340. https://doi.org/10.1016/S0148-2963(03)00069-9

Hrebiniak L.G. (2006). Obstacles to Effective Strategy Implementation. Organizational Dynamics, 35(1), 2006. https://doi.org/10.1016/j.orgdyn.2005.12.001

Hrebiniak, L.G. (2008). Making Strategy Work: Overcoming the Obstacles to Effective Execution. Ivey Business Journal, 72(2), 1-6.

Hrebiniak, L.G., (2005). Business Strategy: Execution is the Key. 1st Edition, by Pearson Education Inc, New Delhi. 
Hrebiniak, L.G. (2013). Making Strategy Work: Leading Effective Execution and Change. 1st Edition, by upper saddle River: Pearson Education Inc., New Jersey, USA.

Hutzschenreuter, T., \& Kleindienst, I. (2006). Strategy-Process research: What Have We Learned and What is Still to be Explored. Journal of Management, 32(5), 673-720. https://doi.org/10.1177/0149206306291485

Jarzabkowski, P., Balogun J, \& Seidl, D. (2007). Strategizing: The Challenges of a practice Perspective. Human Relations, 60(1), 5-27.

Jazabkowski, P., \& Whittington, R. (2008). A Strategy-as-Practice Approach to Strategy Research and Education. Journal of Management Inquiry, 17(4), 282-286. https://doi.org/10.1177/1056492608318150

Johnson, L.K. (2004). Execute Your Strategy Without killing it. Harvard Management Update, 9(12), 3-6.

Kaplan R. S. (2010). Conceptual Foundations of the Balanced Scorecard. Working paper no. 10-074, Harvard, Business School, Boston.

Kaplan R., S., \& Norton D. P. (1996). Linking the Balanced Scorecard to Strategy. California Management Review, 39(1), Fall. https://doi.org/10.2307/41165876

Langley, A. (2007). Process Thinking in Strategic Organization. Strategic Organization, 5(3), 271-282, 2007. https://doi.org/10.1177/1476127007079965

Li Y., Guohi S., \& Eppler M. (2008). ICA working paper, "A Literature Review on Factors Influencing Strategy Implementation. www.knowledge-communication.org

Miller, A., \& Dess, G.G. (1996). Strategic Management" 2nd Edition, by McGraw-Hill Inc. USA.

Noble, C.H, (1999). The Electric Roots of Strategy Implementation Research. Journal of Business Research, 42(2), 119-134. https://doi.org/10.1016/S0148-2963(97)00231-2

Okumus, F. (2001). Towards a Strategy Implementation Framework. International Journal of $\begin{array}{lll}\text { Contemporary Hospitality } \quad \text { Management, } & \text { 13(7), }\end{array}$ 327-338.https://doi.org/10.1108/09596110110403712

Okumus, F. (2003). A Framework to Implement Strategies in Organizations. Management Decision, 41(9), 871-882. https://doi.org/10.1108/00251740310499555

Olson, E., Slater, S., \& Hult, G. (2005). The Importance of Structure and Process to Strategy Implementation. Business Horizons, 84(1), 47-54. https://doi.org/10.1016/j.bushor.2004.10.002

Olum, Y. (2004). Modern Management Theories and Practice. A paper presented on the 15th East-African Central Banking Course, held on 12th July 2004 at Kenya School of Monetrary Studies, 2004. http://www.yolum@ss.mak.ac.ug.

Peters, T., \& Bay, G., (2011). A Brief History of The 7-S ("McKinsey 7-S") Model. New 
Zealand, 09 January 2011. http://www.tompeters.com.

Pettigrew, A. (1997). What is Processual Analysis?. Scandinavian Journal of Management, 13(4), 337-348, December. https://doi.org/10.1016/S0956-5221(97)00020-1

Pryor, M., Anderson, D. Toombs, L., \& Humphreys, J. (2007). Strategic Implementation as a Core Competency: The 5P's Model. Journal of Management Research, 7(1), 3.

Schaap, J.I. (2006). Toward Strategy Implementation Success: An Empirical Study of The Role of Senior-Level Leaders in The Nevada Gaming Industry. Gaming Research and Review Journal, 10, 13-37.

Siddique, I., \& Shadbolt, N. (2016). Strategy Implementation Literature Review. by "Agrione. Center of Excellence in Farm Business Management, Report, March.

Sminia, H. (2009). Process Research in Strategy Formation: Theory, Methodlogy, and Relevance. International Journal of Management Reviews, 11, 97-125.

Verweire K. (2014). Strategy Implementation. First edition, by Routledge, London and New York.

Waterman, R.H, Peters, T.J, \& Philips, J.R. (1980). Structure is not Organization. Business Horizons, 23(3), 14-26, 1980. https://doi.org/10.1016/0007-6813(80)90027-0

Wheelen, T., \& Huger, J. (2012). Concepts in Strategic management and Business policy, 13th Edition, by Pearson / Prentice Hall, Boston, USA.

Whittington, R. (2006). Completing the Practice Turn in Strategy Research. Organization Studies, 27(5), 613-634. https://doi.org/10.1177/0170840606064101 